\title{
Pemikiran Pendidikan Islam pada Era Kontemporer
}

\author{
Sain Hanafy \\ Universitas Islam Negeri (UIN) Hasanuddin Makassar \\ sainha503@gmail.com
}

Abstract: This paper discusses the development of contemporary Islamic education by describing the thoughts of Abdurrahman Mas'ud, Hasan Langgulung, and Abdul Munir Mulkhan. Abdurrahman Mas'ud offers the humanistic and religious format of nondikotomic education, which connects human beings with their God (Hablum Minallah) and between human and human (Hablum Minannas). The purpose of education according to him is to prepare life in the world and the hereafter. Hasan Langgulung offers an idea of the principles of Islamic education. According to him, education can be viewed from two points of view. First, from the perspective of society, that education is a process of cultural inheritance, from the old generation to the younger generation, so that the community can maintain its personality with the basis of Islamic values. Second, from individual perspective, education means the development effort of individual potentials to be actualized concretely so that the results can be beneficial to individuals and society. Langgulung educational thinking is based on the perspective of psychology, education is needed to meet and maintain the sustainability of human life. While Abdul Munir Mulkhan's educational thought is more influenced by a sociological perspective critically. In general, education only prioritizes aspects of intelligence (cognition) and skills (psychomotor), thus ignoring the aspects of personality (emotional). Therefore, he argues, spiritual reasoning is the solution to the philosophical problems of education 
because the personality or consciousness of manners will increase religiosity (spiritual intelligence) as the base of creative consciousness. According to Mulkhan, education is the right of human beings in maintaining humanitarian agreements so that in their life will realize the awareness of pluralism in the society.

Keywords: Development of Contemporary Islamic Education, Education Idea of Abdurrahman Mas'ud, Hasan Langgulung, and Abdul Munir Mulkhan.

\section{Pendahuluan}

Masalah pendidikan bisa diartikan sebagai masalah yang sosial (Don Adams), ${ }^{1}$ yang dari abad selalu muncul sejalan dengan pergeseran abad itu sendiri. Oleh sebab itu, menjadi tanggung jawab para pemikir pendidikan untuk melestarikan dan merekonstruksi bangunan pendidikan tersebut, baik dengan jalan menghadapi pemikiran tokoh Barat atau menggunakan para pemikir Islam klasik sampai kontemporer. Sebagian besar kaum muda Muslim yang datang ke Barat kebanyakan memasuki lembaga Barat, dan pengalaman mereka yang paling dekat adalah pendidikan. Selain itu, juga sebagian generasi muda Muslim menempuh pendidikan di lembaga-lembaga pendidikan Barat dengan tujuan memperkenalkan cara belajar modern kepada kalangan Muslim. Maka dari itu, penting untuk memahami lebih dalam lagi tentang peran dan makna pendidikan.

Disadari atau tidak pendidikan merupakan salah satu saran pembentukan kepribadian yang secara menyeluruh hingga sekarang pendidikan tiada akhirnya menjadi pembicaraan di setiap era klasik atau kontemporer. Di setiap era memiliki corak pendidikan yang berbeda, sehingga hasilnyapun berbeda pula baik dari segi pemikiran maupun watak yang dihasilkan. Di sini penulis mengungkapkan salah-satu tokoh pemikir pendidikan Islam kontemporer, di antaranya Abdurrahman Mas'ud,

\footnotetext{
1 Soetinjanto Wirojoedo, Teori Perencanaan Pendidikan (Yogyakarta: Liberty, 1985), 56.
} 
Hasan Langgulung, Abdul Munir Mulkhan, mencoba akan mengasumsikan tentang perkembangan pemikiran pendidikan Islam.

\section{Pemikiran Tokoh Pendidikan di Indonesia}

Abdurrahman Mas'ud adalah alumni dari pondok pesantren Tebuireng Jombang, Jawa Timur. Maka, corak pemikiran Abdurrahman Mas'ud kental dengan kecenderungan tradisi pesantren. ${ }^{2}$ Setelah kuliah di Amerika, ia kemudian mengedepankan kebebasan, aspek rasional yang jauh dari sentuhan religius, dan sekuler; agama dianggap sebagai urusan pribadi. ${ }^{3}$

Dalam buku Menggagas Format Pendidikan Nondikotomik, Abdurrahman Mas'ud menyatakan bahwa tujuan pendidikan ialah untuk mencapai keberhasilan dalam kehidupan di dunia dan akhirat, yang berkaitan pada hubungan antara manusia dengan Tuhannya (hablum min Allah) dan hubungan antara manusia dengan manusia (hablum minannas). Dalam hal ini Mas'ud menawarkan konsep humanisme ${ }^{4}$ religius, yang jika diimplementasikan dalam dunia pendidikan Islam akan berfokus pada akal sehat (common sense). ${ }^{5}$

Pada konteks lain, Hasan Langgulung lebih fokus pada persoalan psikologi dan pendidikan Islam. Pemikiran Langgulung dipengaruhi oleh kondisi bangsa Indonesia yang memprihatinkan dalam hegemoni penjajahan. Keadaan politik, kultur, sosial dan ekonomi mengalami masa keterpurukan tersebut berimbas pada ranah pendidikan. Hal itu terbukti dengan adanya politik penjajahan agar rakyat terjajah terbelenggu dalam

\footnotetext{
2 Abdurrahman Mas'ud, Menggagas Format Pendidikan Nondikotomik: Humanisme Religius Sebagai Paradigma Pendidikan Islam (Yogyakarta: Gema Media, 2002), xiii.

3 Isma’il SM, Nurul Huda, Abdul Khaliq (eds.), Paradigma Pendidikan Islam, Cet. I (Semarang: Pustaka Belajar \& Fakultas Tarbiyah IAIN Walisongo, 2001), 3-4.

4 Humanisme adalah merupakan suatu doktrin yang menemukan kepentingankepentingan kemanusiaan dan ideal. Pius A. Partanto \& M. Dahlan al-Barry, Kamus Ilmiah Populer (Surabaya: Arkola, 1998), 235.
}

5 Mas'ud, Menggagas Format Pendidikan, 193. 
kebodohan. Dalam kondisi semacam inilah yang melatarbelakangi pemikiran Hasan Langgulung. Selain itu, karena luasnya pengalaman dan keilmuannya dalam bidang pendidikan dan psikologi. ${ }^{6}$

Berkaitan dengan pendidikan Hasan Langgulung memperincinya dalam dua hal, yaitu pendidikan secara umum dan dalam tinjauan Islam. Menurut Langgulung, pengertian pendidikan dapat ditinjau dua segi, yaitu segi pandang masyarakat dan dari segi pandang individu. Dari segi pandang masyarakat pendidikan itu sebagai pewaris kebudayaan atau nilai-nilai budaya baik yang bersifat intelektual, keterampilan, keahlian darigenerasi tua ke generasi muda agar masyarakat tersebut dapat memelihara kepribadiannya. Dari segi individu berarti upaya pengembangan potensi-potensi individu yang masih terpendam agar dapat teraktualisasi secara kongkret sehingga hasilnya bisa dinikmati untuk individu dan masyarakat. Tetapi, kemudian muncul pandangan ketiga tentang pendidikan, yaitu sekaligus memandang dari segi masyarakat atau alam jagat dan dari segi individu. ${ }^{7}$ Bila makna pendidikan tersebut ditarik ke dalam pendekatan Islam akan melahirkan pendidikan, yang menurut Langgulung, sebagai suatu proses baik dalam spiritual, akhlak, intelektual, maupun sosial, yang berupaya membimbing manusia dan memberinya nilai-nilai, prinsip-prinsip dan teladan ideal dalam kehidupan yang bertujuan mempersiapkan kehidupan dunia dan akhirat ${ }^{8}$ - dalam konteks Ibnu Qayyim, ${ }^{9}$ hakikat dan tujuan pendidikan adalah menjaga fitrah ${ }^{10}$ manusia dan mewujudkan agar tidak jatuh dalam penyimpangan, serta mewujudkan dalam dirinya untuk ubudiyah (penghambaan) kepada Allah. Dengan demikian, tujuan pendidikan menurut Langgulung tidak

${ }^{6}$ Hasan Langgulung, Pendidikan dan Peradaban Islam (Jakarta: Pustaka al-Husna, 1983), 172.

7 Hasan Langgulung, Asas-asas Pendidikan Islam (Jakarta: al-Husna, 2000), 2.

8 Ibid., 38.

9 Hasan bin Ali Hasan, Manhaj Tarbiyah Ibnu Qayyim, Cet. I (Jakarta: Pustaka Al-Kausar, 2001), 83.

${ }^{10}$ Fitrah adalah sebagai yang suci sesuai dengan asal kejadian alam dan manusia ketika asal pertama diciptakan Tuhan. M. Dawam Raharjo, Ensiklopedi al-Qur'an Konsep-konsep Kunci (Jakarta: Paramadina, 1996), 59. 
terlepas dari tujuan hidup, yaitu untuk memenuhi kehidupan manusia, ${ }^{11}$ sebab pendidikan hanya alat yang digunakan oleh manusia untuk memelihara kelanjutan hidup baik secara individu ataupun kelompok. ${ }^{12}$

Abdul Munir Mulkhan sebagai seorang pemikir yang menyumbangkan pemikirannya di abad kontemporer, banyak mengalisis para pemikir sebelumnya. Pemikiran Mulkhan lebih menekankan pada kecenderungan sosiologis. Manusia dalam menjelaskan pendidikan sama halnya dengan kewenangan hak manusia dalam segala yang ada dan mempertahankan pemahaman sepanjang kesepakatan-kesepakatan kemanusiaan di mana mereka hidup. Maka harus disimpulkan bahwa Islam memberi wewenang kepada manusia untuk memikirkan dan menjalakannya di atas prinsip keterbatasan dan kemampuan manusia tersebut. ${ }^{13}$ Dalam hal ini tujuan pendidikan yang ingin dicapai oleh Mulkhan hampir tidak ada perbedaan dari para pemikir kontemporer lainnya, yaitu untuk mencapai kebahagiaan dunia dan akhirat. Dan tiada pemisahan antara ilmu umum dan ilmu agama, agar seorang muslim, ulama cendekiawan dapat terhindar dari pengertian dikotomik. ${ }^{14}$

\section{Perkembangan Pemikiran Pendidikan Islam}

Mengenai perkembangan dalam pemikiran pendidikan, Abdurrahman Mas'ud menawarkan konsep religius pluralis dalam praktik pendidikan Islam. Implementasi dari konsep Abdurrahman Mas'ud tersebut dapat dilihat dalam bukunya Format Pendidikan Islam, yang membagi lima aspek dalam pendidikan.

Guru. Bagi Mas'ud kualifikasi dasar seorang guru ialah menguasi materi dan antusiasme dalam mengajar dan mendidik sebab tujuan

\footnotetext{
${ }^{11}$ Hasan Langgulung, Manusia dan Pendidikan (Jakarta: Radarjaya Offset, 1986), 33.

12 Zuhairini, Filsafat Pendidikan Islam (Jakarta: Bumi Aksara, 1991), 15.

${ }^{13}$ Abdul Munir Mulkhan, Paradigma Intelektual Muslim, Pengantar Filsafat Pendidikan Islam dan Dakwah (Yogyakarta: Sipress, 1993), 9.

${ }^{14}$ Abdul Munir Mulkhan, Ideologisasi Gerakan Dakwah Episode Kehidupan M. Nafsir dan Azhar Basyir (Yogyakarta: Sipress, 1996), 203.
} 
utama guru adalah mencerdaskan. Proses pencerdasan harus berangkat dari pandangan bahwa pada dasarnya anak didik memiliki kemampuan dan keterampilan. ${ }^{15}$ Dalam konteks humanisme religius seorang guru di sekolah harus dengan kasih sayang mendidik anak didik sebagai individu yang shalih.

Metode berarti upaya perbaikan semua elemen pendidikan secara komprehensif dalam mendukung tercapainya tujuan pendidikan. Oleh karena itu, guru harus mengenal setiap pribadi anak didiknya secara individual. Hal ini dilakukan upaya-upaya dalam rangka pengembangan kreativitas, meningkatkan kepekaan sosial, penajaman hati nurani dan religiositas setiap anak didik. ${ }^{16}$

Murid. Ali Bin Abi Tholib memberikan syarat bagi anak didik dengan enam macam yang merupakan kompetensi mutlak dan dibutuhkan untuk mencapai tujuan pendidikan syarat yang dimaksud.

Ingatlah! Engkau tidak bisa memeroleh ilmu kecuali karena enam syarat, aku akan menjelaskan syarat itu padamu, yaitu kecerdasan (akal), motivasi atau kemauan yang keras, sabar, alat (sarana), petunjuk guru, dan terus-menerus (continue) atau tidak bosan mencari ilmu (konsisten). ${ }^{17}$

Dari syair tersebut dapat dipahami bahwa enam syarat bagi pencari ilmu adalah mencakup kecerdasan (akal) anak didik atau kecerahan penalaran, mempunyai greget (ghiroh) atau motivasi yang tinggi dalam mencari ilmu, serta tidak mudah putus asa walaupun banyak rintangan dan hambatan, baik hambatan ekonomi, sosial, politik, dan sebagainya. Di samping itu, syarat-syarat pencari ilmu lainnya adalah mempunyai seperangkat sarana yang memadai, adanya petunjuk pendidikan

\footnotetext{
${ }^{15}$ Mas'ud, Menggagas Format Pendidikan, 194.

${ }^{16}$ Dalam hal ini pihak yang bertanggung jawab tidak hanya guru di sekolah, tapi juga perlu peran orang tua, lingkungan tetangga, keamanan pemerintah, serta kaum agamawan. Ibid., 197.

${ }^{17}$ az-Zarnuji, Syaikh Burhanuddin. Ta’limul Muta'allim fi Thoriq Ta'allum (Surabaya: Maktabah Nabhaniyah Kubro, tt.), 15.
} 
sehingga tidak terjadi salah pengertian (misunderstanding) terhadap apa yang dipelajari, dan tiada hentinya-hentinya mencari ilmu sampai pada akhir hayat (no limits to study). Menurut pengamatan Mas'ud lebih cermat terhadap enam syarat itu menunjukkan hal yang berbeda, sebab pada prinsipnya pendidikan Islam pada masa klasik jelas memperoleh pijakan biologis dari keenamnya.

Materi. Beberapa hal yang perlu diperhatikan dalam materi pembelajaran baik dalam pengajaran umum maupun pengajaran agama harus mampu melahirkan kreativitas, moralitas (akhlak), dan memotivasi anak didik dengan lebih memberikan apresiasi dari pada sanksi (hukuman). Sebagai contoh dalam humanisme religius pengajaran Aswaja, materimateri ideologis diberikan sebagai dasar bagi santri di pondok pesantren.

Evaluasi. Evaluasi hendaknya dilakukan dalam dua arah, yakni baik guru maupun anak didik diberi kesempatan menilai kemampuannya. Dalam humanisme religius, anak didik dipandang sebagai individu yang berhak mengambil keputusan sebagai bentuk pembelajaran atas sikap tanggung jawab.

\section{Asas-Asas Pendidikan Islam}

Di dalam perkembangan pemikiran pendidikan Islam Langgulung terfokus kedua arah di antaranya pendidikan dan psikologi. Dengan kedua aspek ini, Langgulung memperinci kepada pendidikan di pandang dari sudut masyarakat dan dari segi individual. Sudut pandang ketiga inilah yang menjadi tinjauan psikologi. Dari semua penjabaran di atas pada intinya pendidikan suatu proses pewarisan budaya yang dapat dimanfaatkan individual masyarakat dengan dilandasi nilai-nilai Islam. Bagi Langgulung, baik pendidikan secara umum maupun pendidikan Islam tidak akan bisa berdiri bila mengesampingkan asas-asas pendidikan. Asas-asas pendidikan Islam menurut Langgulung, di antaranya, pertama, asas historis yang mempersiapkan si pendidik dengan hasilhasil pengalaman pengalaman masa lalu, dengan undang-undang dan peraturan-peraturannya. Batas-batas dan kekurangan-kekurangannya. 
Kedua, asas-asas sosial yang memberi kerangka budaya dari mana pendidikan itu bertolak dan bergerak, memindah budaya, memilih, dan mengembangkannya. Ketiga, asas-asas ekonomi yang memberi perspektif dengan potensi-potensi manusia dan keuangan, materi, dan persiapan yang mengatur sumber-sumber dan bertanggung jawab terhadap anggaran belanja. Keempat, asas-asas politik dan administrasi yang memberi bingkai ideologi (akidah) dari mana ia bertolak untuk mencapai tujuan yang dicita-citakan dan rencana yang telah dibuat. Kelima, asas-asas psikologis yang memberi informasi tentang watak pelajar-pelajar, guruguru, cara-cara terbaik dalam praktik, pencapaian dan penilaian dan bimbingan. Keenam, asas-asas filsafat yang berusaha memberi kemampuan memilih yang lebih baik, memberi arah suatu sistem, mengontrol dan memberi arah kepada sesama asas-asas yang lain.

Asas-asas pendidikan Islam di satu sisi bermakna sebagai berikut: Pertama, asas pendidikan atau dasar pendidikan Islam yang dimaksud adalah nilai-nilai tertinggi yang dijadikan pandangan hidup suatu masyarakat pada pendidikan tersebut, maka sumber nilai pendidikan Islam adalah al-Qur'an, Sunnah dan hasil ijtihad yang mengandung nilai yang fundamental, yaitu tauhid sebagai seluruh asas pendidikan Islam yang akhirnya mengarah pada hamba Allah yang beriman dan bertakwa.

Kedua, kemanusiaan; adanya pengakuan kemuliaan manusia karena memiliki harkat, martabat yang terbentuk dari kemampuan kejiwaan yang digerakkan oleh akal, nilai kemanusiaan dijadikan dasar pendidikan Islam karena proses pendidikan Islam menjamin potensi kemanusiaan atau fitrah manusia. Indikasi tersebut merujuk pada kesempatan setiap manusia untuk memperoleh pendidikan tanpa dibedakan.

Ketiga, kesatuan umat manusia, Hasan Langgulung mengungkapkan bahwa pandangan hidup umat yang bertuhankan Allah adalah satu. Begitu juga dalam segala pemikiran. Perasaan dan tindakan ada konsensus untuk menjadikan syariat sebagai penguasa berakhir untuk menyelesaikan perbedaan antara mereka, persaudaraan sejagat yang tidak mengenal perbedaan warna dan etnis hanya terjadi apabila didasarkan pada nilai-nilai Islam. Siapa saja yang memilih Islam sebagai agamanya 
dan ia termasuk anggota umat yang diberi hak dan tanggung jawab yang diwajibkan syariah.

Keempat, keseimbangan. Langgulung mengatakan Islam tidak menentang pengalaman keagamaan dari manapun asalnya asal baik dan tidak dilarang Islam adalah meminjam sepenuhnya sistem-sistem non Islam seluruhnya. Nilai keseimbangan antara kepentingan dunia akhirat, jasmani rohani, individu sosial, ilmu, dan amal.

Kelima, rahmatul lil alamin; dengan demikian seluruh proses pendidikan Islam yang berfungsi sebagai sarana pengembangan potensi individu dan pemindahan individu ilmu dan pewarisan budaya, harus selalu bersumber pada nilai-nilai ilahiah (rahmatan lil alamin) sehingga akan mendatangkan manfaat bagi seluruh kehidupan. Hal ini sesuai dengan tujuan Allah mengutus Rasulullah bukan untuk segolongan umat saja, melainkan seluruh umat manusia dan seluruh isi alam semesta ini. ${ }^{18}$

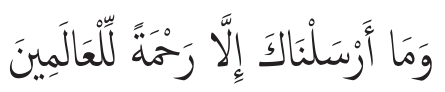

Dan kami mengutusmu melainkan rahmat bagi seluruh alam semesta. (Q.S. al-Anbiya': 107)

Untuk menentukan teori belajar, maka Langgulung merujuk segi sejarah yang teori-teori tersebut dapat diklasifikasikan pada dua golongan.

Pertama, Teori Asosiasi. Teori ini termasuk utama dalam behaviorisme, pendapat teori ini bahwa proses belajar itu menurut persyaratan tingkah laku, maka perlu sekali peneguran alami (harga diri, pujian, perhatian) untuk memelihara tingkah laku tersebut, dan tidak menafikan peneguhan bikinan (makanan, uang) untuk memulai tingkah laku. Dari teori ini dapat disimpulkan, proses belajar melibatkan rangsangan yang mempengaruhi individu, suatu respons yang dibuat individu dan perlautan (connection) antara rangsangan dan respons (peraturan) S-R pertautan asosiasi kuat ia prehabilitas bahwa ia akan lain dan lemah bila

\footnotetext{
${ }^{18}$ H. Oemar Bakry, Tafsir Rahmat (Jakarta: Mutiara, 1983), 637.
} 
prehabilitas kecil.

Kedua, Teori Lapangan. Termasuk teori cabang utama dalam kognivitisme menurut teori ini, proses belajar suatu perubahan dalam cara-cara memandang lingkungan seseorang, teori ini menentang teori asosiasi (S-R) bahwa Allah akan menciptakan khalifah di bumi, maka manusia dianggap sebagai mikrokosmos (jagad besar).

Perkembangan pemikiran pendidikan Islam Abdul Munir Mulkhan adalah mengarah kepada bentuk belajar, dimana fokus utama pendekatan diletakkan pada tumbuhnya kepintaran anak, yaitu kepribadian yang sadar diri atau kesadaran budi pekerti sebagai pangkal dari kesadaran kreatif. Teori yang dipakai mengenai peranan SQ, IQ, EQ.

Selama ini dari tiga ranah kecerdasan (kognisi), keterampilan (psikomotor), kepribadian atau afeksi, kecerdasan IQ dan keterampilan dalam praktik pendidikan lebih dipentingkan, sementara ranah kepribadian kurang diperhatikan sewajarnya. Ini menjadikan kecerdasan manusia berdasarkan otaknya, sehingga muncul teori tentang cara mengukur kecerdasan otak yang dikenal dengan IQ. Dalam pendidikan juga di perlukan adanya teori kecerdasan emosional yang menyatakan bahwa kemampuan diri (nafsu) sebagai inti EQ adalah akar kecerdasan yang lebih penting dari IQ. Maka, timbullah teknik belajar yang disebut Quantum Learning. Selain itu, juga perlu adanya kecerdasan spiritual (SQ) yang muncul dari pemikiran filosofis yaitu mengenai kemampuan hati nurani "kata hati" yang hebat dari semua jenis kecerdasan SQ dan EQ dipandang lebih unsur pokok yang menjadikan seseorang bisa mencapai kesuksesan mengatasi masalah yang dihadapi.

Menurut keyakinan tokoh-tokoh SQ, kemampuan SQ yang tinggi seseorang mampu dipakai untuk meningkatkan religiusitas (rasa Keagamaan) seseorang. ${ }^{19}$ Berhentinya pertumbuhan emosi atau budi pekerti yang bersih tampak dalam berbagai peristiwa kekerasan dan berbagai teror Bom yang belakangan terus berkembang di tanah air, seperti BEJ,

${ }^{19}$ Zohar Danah, SQ Spiritual Intelligence: The Ultimate Intelligence (London: Bloomsbry Publishing, 2000), 285. 
malam Natal, Konflik Maluku, Sambas, dan sebagainya. ${ }^{20}$

\section{Penutup}

Demikian perkembangan pendidikan Islam kontemporer dengan penguraian pemikiran-pemikiran Abdurrahman Mas'ud, Hasan Langgulung, dan Abdul Munir Mulkhan. Abdurrahman Mas'ud menawarkan format pendidikan non dikotomik yang humanis dan religius, yakni pendidikan yang menghubungkan antara manusia dengan Tuhannya (hablum minallah) dan antara manusia dengan manusia (hablum minannas). Tujuan pendidikan menurutnya ialah mempersiapkan kehidupan di dunia dan akhirat. Sedangkan Hasan Langgulung menawarkan gagasan tentang asas-asas pendidikan Islam. Menurutnya, pendidikan dapat ditinjau dari dua sudut pandang. Pertama, dari sudut pandang masyarakat, bahwa pendidikan adalah suatu proses pewarisan budaya, dari generasi tua ke generasi muda agar masyarakat tersebut dapat memelihara kepribadiannya dengan dilandasi oleh nilai-nilai Islam. Kedua, dari sudut pandang individu, pendidikan berarti upaya pengembangan potensi-potensi individu agar dapat teraktualisasikan secara kongkret sehingga hasilnya bisa dinikmati untuk individu dan masyarakat. Pemikiran pendidikan Langgulung ini dilandasi oleh perspektif psikologi, pendidikan diperlukan untuk memenuhi dan memelihara keberlangsungan kehidupan manusia.

Sedangkan pemikiran pendidikan Munir Mulkhan lebih banyak dipengaruhi oleh perspektif sosiologis secara kritis. Pada umumnya pendidikan yang hanya mengutamakan aspek kecerdasan (kognisi) dan keterampilan (psikomotor) sehingga mengabaikan aspek kepribadian (emosional). Oleh karena itu, menurutnya, perlu adanya nalar spritual sebagai solusi atas problem filosofis pendidikan sebab kepribadian atau kesadaran budi pekerti akan meningkatkan religiositas (kecerdasan spiritual) sebagai pangkal dari kesadaran kreatif. Menurut Mulkhan, pendidikan adalah hak manusia dalam mempertahankan kesepakatankesepakatan kemanusiaan sehingga dalam kehidupan mereka akan terwujud kesadaran pluralisme dalam bermasyarakat.

\footnotetext{
${ }^{20}$ Abdul Munir Mulkhan, Nalar Spiritual Pendidikan Solusi Problem Filosofis Pendidikan (Yogyakarta: Tiara Wacana: 2002), 71.
} 


\section{DAFTAR PISTAKA}

Bakry, H. Oemar. Tafsir Rahmat. Jakarta: Mutiara, 1983.

Danah, Zohar. SQ Spritual Inteligence: The Ultimate Intelligence. London: Bloomsbry Publishing, 2000.

Hasan, Hasan bin Ali. Manhaj Tarbiyah Ibnu Qayyim. Cet. I. Jakarta: Pustaka al-Kautsar, 2001.

Isma'il SM, Nurul Huda, Abdul Khaliq (eds.). Paradigma Pendidikan Islam, C et. I. Semarang: Pustaka Belajar \& Fak. Tarbiyah IAIN Walisongo, 2001.

Langgulung, Hasan. Pendidikan dan Peradaban Islam. Jakarta: Pustaka al-Husna, 1983. . Manusia dan Pendidikan. Jakarta: Radarjaya Offset, 1986. . Asas-asas Pendidikan Islam. Jakarta: al-Husna, 2000.

Marimbah, Ahmad D. Pengantar Filsafat Pendidikan Islam, Cet. VIII. Bandung: al-Ma’arif, 1989.

Mas'ud, Abdurrahman. Menggagas Format Pendidikan Nondikotomik, Humanisme Religius Sebagai Paradigma Pendidikan Islam. Yogyakarta: Gema Media, 2002.

Mulkhan, Abdul Munir. Paradigma Intelektual Muslim: Pengantar Filsafat Pendidikan Islam dan Dakwah. Yogyakarta: Sipress, 1993. . Ideologisasi Gerakan Dakwah Episode Kehidupan M. Nafsir dan Azhar Basyir. Yogyakarta: Sipress, 1996.

. Nalar Spiritual Pendidikan Solusi Problem Filosofis Pendidikan. Yogyakarta: Tiara Wacana: 2002.

Partanto, Pius A. \& M. Dahlan al-Barry. Kamus Ilmiah Populer. Surabaya: Arkola, 1998.

Raharjo, Dawam. Ensiklopedi al-Qur'an Konsep-konsep Kunci. Jakarta: Paramadina, 1996. 
Tafsir, Ahmad. Ilmu Pendidikan dalam Perspektif Islam. Cet. II. Bandung: Remaja Rosdakarya, 1994.

Wirojoedo, Soetinjanto. Teori Perencanaan Pendidikan. Yogyakarta: Liberty, 1985.

az-Zarnuji, Syaikh Burhanuddin. Ta'limul Muta'allim fi Thoriq Ta'allum. Surabaya: Maktabah Nabhaniyah Kubro, tt.

Zuhairini. Filsafat Pendidikan Islam. Jakarta: Bumi Aksara, 1991. 